J. Lake Sci.(湖泊科学), 2009, 21(2): 165-172

http://www.jlakes.org. E-mail: jlakes@niglas.ac.cn

(C)2009 by Journal of Lake Sciences

\title{
太湖真光层深度的计算及遥感反演*
}

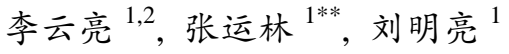 \\ (1: 中国科学院南京地理与湖泊研究所湖泊与环境国家重点实验室, 太湖湖泊生态系统研究站, 南京 210008) \\ (2: 南京大学地理与海洋科学学院, 南京 210093)
}

摘 要: 真光层是浮游植物进行光合作用的水层, 真光层反演有利于初级生产力的进一步估算. 利用2007-01-07和2006-08-01 两期陆地卫星 $\mathrm{TM}$ 数据与同步水质参数数据, 建立太湖水体非色素颗粒物浓度和叶绿素a浓度的反演模型, 反演出太湖冬、夏两季 的非色素颗粒物、叶绿素a浓度. 然后根据在太湖建立的真光层深度与非色素颗粒物、叶绿素a浓度之间的关系模型，计算得到太 湖冬、夏两季真光层深度空间分布. 结果表明, 就整个湖区而言, 冬季真光层深度变化范围为 $0.27-2.28 \mathrm{~m}$, 均值为 $0.56 \pm 0.22 \mathrm{~m}$, 夏 季真光层深度变化范围为 $0.21-2.03 \mathrm{~m}$, 均值为 $0.98 \pm 0.24 \mathrm{~m}$. 从空间上看, 冬季时真光层深度的变化规律为: 南太湖<西部沿岸<湖 心区 $<$ 胥口湾 $<$ 贡湖湾 $<$ 梅梁湾 $<$ 东太湖 $<$ 竺山湾; 夏季时的变化规律为: 西部沿岸 $<$ 梅梁湾 $<$ 东太湖 $<$ 湖心区 $<$ 贡湖湾 $<$ 竺山湾 $<$ 南太 湖 $<$ 胥口湾. 从季节上看, 夏季真光层深度显著大于冬季, 但不同湖区真光层深度季节变化也存在一定差异, 其中梅梁湾、贡湖 湾、西部沿岸、湖心区、胥口湾、南太湖夏季真光层深度大于冬季, 而竺山湾和东太湖夏冬变化则不是很明显.

关键词: 太湖; 真光层深度; 非色素颗粒物; 叶绿素 a; 反演

\section{Calculation and retrieval of euphotic depth of Lake Taihu by remote sensing}

\author{
LI Yunliang ${ }^{1,2}$, ZHANG Yunlin ${ }^{1} \&$ LIU Mingliang ${ }^{1}$ \\ (1: Lake Taihu Laboratory Ecosystem Research Station, State Key Laboratory of Lake Science and Environment, Nanjing Institute of \\ Geography and Limnology, Chinese Academy of Sciences, Nanjing 210008, P.R.China) \\ (2: School of Geography and Ocean Sciences, Nanjing University, Nanjing 210093, P.R.China)
}

Abstract: The euphotic zone is defined as the layer where net phytoplankton production is positive. Therefore, determination of the euphotic depth is useful for estimating primary production. The TM data on 2007-01-07 and 2006-08-01, accompanied by real-time water quality parameters including concentrations of tripton and chlorophyll-a (Chl.a) in Lake Taihu, were used to develop quantitative retrieval models of tripton and Chl.a. Euphotic depth was calculated using the model developed in Lake Taihu based on the concentrations of tripton and Chl.a. The euphotic depth ranged from 0.27 to $2.28 \mathrm{~m}$ (mean $0.56 \pm 0.22 \mathrm{~m}$ ) in winter depth from 0.21 to $2.03 \mathrm{~m}$ (mean $0.98 \pm 0.24 \mathrm{~m}$ ) in the summer. In the winter, the euphotic depths showed spatial distributions which were ordered as : the south of Lake Taihu $<$ the west coast of Lake Taihu $<$ the lake center $<$ Xukou Bay $<$ Gonghu Bay $<$ Meiliang Bay $<$ East Lake Taihu $<$ Zhushan Bay. In summer, the order changed as follows: the west coast of Lake Taihu $<$ Meiliang Bay $<$ East Lake Taihu < the lake center < Gonghu Bay < Zhushan Bay < the south of Lake Taihu. Seasonally, the euphotic depth was significantly shallower in summer than in winter; however, seasonal variation differed among areas of the lake. Euphotic depths in Meiliang Bay, Gonghu Bay, the west coast of Lake Taihu, the lake center, Xukou Bay and the south of Lake Taihu were higher in the summer than in the winter, but no marked seasonal variations were found in Zhushan Bay and East Lake Taihu.

Keywords: Lake Taihu; euphotic depth; tripton; chlorophyll-a; retrieval

真光层深度 (euphotic depth)一般指光强下降到水面光强 $1 \%$ 的深度, 也有人将水下光强为 $14 \mu \mathrm{mol} /\left(\mathrm{m}^{2} \cdot \mathrm{s}\right)$

* 中国科学院知识创新工程项目(KZCX1-YW-14-2, KZCX2-YW-419)和国家自然科学基金重点项目(40730529)联合资助。 2008-10-01 收稿; 2008-12-15 收修改稿. 李云亮, 女, 1983 年生, 硕士研究生; E-mail: liyunliang83@163.com.

** 通讯作者; E-mail: ylzhang@niglas.ac.cn. 
对应的深度称为真光层深度 ${ }^{[1]}$. 真光层深度是描述水体表观光学特性的重要参数之一, 它能表征水体 的清澈程度, 且比透明度更为准确. 真光层深度受制于水体中非色素颗粒物、浮游植物和有色可溶性有 机物(Chromophronic Dissolved Organic Matter, CDOM) 浓度和组成 ${ }^{[2]}$. 由于浮游植物和沉水植物光合作用 主要发生在这一层, 因此真光层深度直接影响到浮游植物初级生产力和沉水植物的分布 ${ }^{[3-4]}$.

目前, 计算真光层深度最常见的方法有两种, 一种是用Secchi圆盘测得透明度, 进而推算真光层深度 ${ }^{[5-7]}$, 一种是根据可见光漫射衰减系数, 利用辐射传输模式 ${ }^{[8-9]}$, 反演出真光层深度. 这两种方法操作起来 都费时费力, 大面积的同步获取水体真光层深度存在着比较大的困难. 随着遥感技术的发展、水色遥感 的广泛应用, 水质参数的大面积观测、大尺度调查成为可能, 遥感手段为真光层的计算提供了新的方法.

水体真光层的遥感计算一般有 2 种模式: 一是机理模式, 即利用真光层深度与水体漫衰减系数的关 系, 根据辐射传输模型计算出真光层深度 ${ }^{[10-12]}$; 另一种是统计模式, 很多学者发现真光层深度与某种或 多种水质参数(透明度、叶绿素和悬浮物浓度)之间有着较好的统计关系 ${ }^{[13-17]}$. 如在大洋水体往往通过叶绿 素浓度来计算真光层深度, 而对于以非色素颗粒物为主的浑浊二类水体, 真光层深度很大程度上受制于 非色素颗粒物浓度, 其次才是叶绿素a浓度 ${ }^{[18-20]}$

本文尝试利用2007-01-07和2007-08-01两期陆地卫星TM数据与同步地面水质参数数据, 建立太湖 水体非色素颗粒物浓度和叶绿素a浓度的反演模型, 反演出太湖冬、夏季非色素颗粒物、叶绿素a浓度, 然 后根据真光层深度与非色素颗粒物、叶绿素a浓度之间关系模型, 通过遥感手段反演出冬、夏季太湖真光 层深度

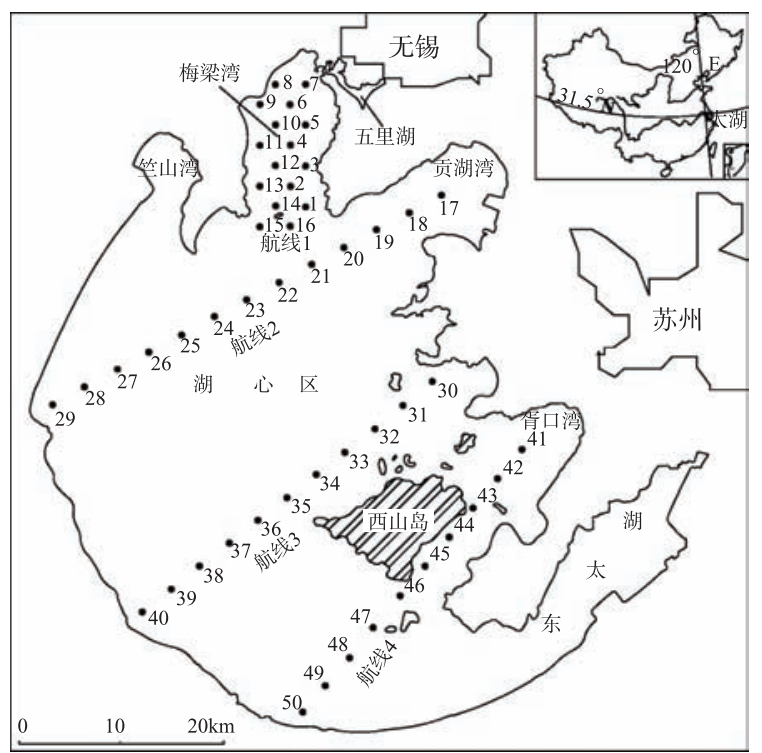

图1 太湖采样站点分布

Fig.1 Distribution of sampling stations of Lake Taihu

\section{1 材料与方法}

\section{1 采样与测量方法}

2006-07-29 至 2006-08-01 和 2007-01-07 至2007-01-09在太湖水面分别布设50个采样点 (图1), 进行了表层水质采样, 样点分布在4条航 线，基本覆盖了太湖不同生态类型的湖区. 采 样期间风速均较小, 因此藻华在不同湖区间漂 移堆积的变化不会太明显.

此外，从2003到2007年对全湖共进行了14 次采样，样点分布均匀，遍布全湖，涵盖了各个 季节, 共得到298个采样点的非色素颗粒物、叶 绿素a浓度与漫射衰减系数.

悬浮物用GF/C滤纸过滤, 采用电子天平称 重法测定. 叶绿素 $\mathrm{a}$ 的测定采用分光光度法, 用 90\%的热酒精萃取提取色素，然后在分光光度 计上测定吸光度换算得到叶绿素 $\mathrm{a}$ 和脱镁叶绿 素浓度 ${ }^{[21]}$. 为了从总悬浮物中分离得到非色素 颗粒物, 在实验室培养太湖优势藻种微囊藻和 栅列藻, 在其不同生长阶段测定浮游植物干重和色素浓度. 同时在风平浪静的天气下，从太湖取表层水 华回实验室用蒸馏水清洗得到较为纯的浮游植物样品, 然后置于黑暗条件下让其自然降解, 定期取样测 定浮游植物干重和色素浓度. 从而得到浮游植物干重与色素浓度的换算关系, 而非色素颗粒物浓度为总 悬浮物浓度与浮游植物干重之间的差值 ${ }^{[20]}$

$$
\begin{gathered}
C_{\text {phytoplankton }}=0.09 C_{\text {Chl.a }+\mathrm{Pa} a}\left(r^{2}=0.98, n=31, P<0.001\right) \\
C_{\text {Tripton }}=C_{\mathrm{TSM}}-C_{\text {phytoplankton }}
\end{gathered}
$$

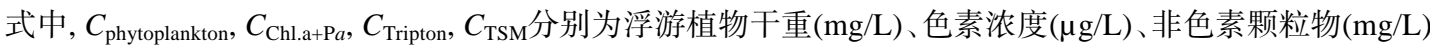
和总悬浮物浓度 $(\mathrm{mg} / \mathrm{L})$. 
漫射衰减系数按下式计算 ${ }^{[2]}$ :

$$
K_{\mathrm{d}}(\mathrm{PAR})=-\frac{1}{z} \ln \frac{E_{\mathrm{d}}(\mathrm{PAR}, z)}{E_{\mathrm{d}}(\mathrm{PAR}, 0)}
$$

式中, $K_{\mathrm{d}}(\mathrm{PAR})$ 为 PAR 漫射衰减系数, $z$ 为从湖面到测量处的深度, $E_{\mathrm{d}}(\mathrm{PAR}, z)$ 为深度 $z$ 处的向下辐照度, $E_{\mathrm{d}}(\mathrm{PAR}, 0)$ 为水面起始向下辐照度, 其测定选用美国 LI-COR 公司的 Li-cor 192SA 水下光量子仪, 分水下 $0,0.2,0.5,0.75,1.0,1.5 \mathrm{~m}$ 共 6 层, 每层记录 3 个数据, 取平均值. $K_{\mathrm{d}}(\mathrm{PAR})$ 值通过对不同深度处水下辐照度 进行指数回归得到, 回归效果只有当 $r^{2} \geq 0.95$, 深度数 $n \geq 3$ 时其 $K_{\mathrm{d}}$ (PAR)值才被接受, 实际拟合的效果 $r^{2}$ 的均值为 0.9964 .

\section{$1.2 \mathrm{TM}$ 数据预处理}

本次选用的两期陆地卫星TM影像的获取时间分别为2007-01-07和2006-08-01，基于ENVI 4.3软件 作如下的预处理:

(1)以一幅已经进行过精纠正的TM影像(投影为UTM，椭球体为WGS84)为底图，对两期遥感图像进 行几何精纠正, 总误差RMS控制在 0.5 个象元之内, 图像重采样采用最近邻近点法, 投影选择UTM投影;

(2)采用6S软件对两期影像进行大气校正, 校正时需要输人的主要参数有: 太阳天顶角、卫星天顶角、 太阳方位角、卫星方位角(这些参数可以从 $\mathrm{TM}$ 影像头文件中获得); 大气组分参数，包括水汽、灰尘颗粒 度等参数(本次因缺乏大气实测数据, 就选用 65 提供的标准大气模型一一纬度夏天和中纬度冬天来替 代); 气溶胶组分参数，包括水分浓度以及烟尘、灰尘等在空气中的百分比等参数(本次选用 “大陆模型”来 描述标准大气的气溶胶组分等); 气溶胶的大气路径长度(本次用能见度参数表示); 观测目标的海拔高度 及传感器高度; 光谱条件(可以直接输人光谱波段范围,也可以将遥感器波段作为输人条件). 6S 软件在有 关参数输人完毕后会计算出各种大气参数, 同时也给出了大气校正系数 $x_{a}, x_{b}, x_{c}$, 大气校正后的反射率 ACR (Atmospherically corrected reflectance)可以用下式获得:

$$
\begin{gathered}
Y=\chi_{a} L_{i}-\chi_{b} \\
A R C=Y /\left(1+x_{c} Y\right)
\end{gathered}
$$

式中, $L_{i}$ 为第波段的辐亮度值.

(3)利用阈值法以及目视判读, 确定水域, 制作水域掩膜, 利用掩膜进行图像的掩膜操作, 提取水域.

\section{2 结果与讨论}

\section{1 真光层深度计算式}

真光层定义为辐照度为水表面辐照度 $1 \%$ 的上层水域, 在光学性质均一的水体内, 透过水域的光线遵 从Lambert定律, 即辐照度随着深度的增加呈指数衰减. 假定真光层深度为 $\mathrm{Z}_{\mathrm{eu}}$, 由式(3)可推导出如下真 光层深度计算式 ${ }^{[2]}$ :

$$
\mathrm{Z}_{e u}(\mathrm{PAR})=-\frac{1}{K_{\mathrm{d}}(\mathrm{PAR})} \ln \frac{1 \% E_{\mathrm{d}}(\mathrm{PAR}, 0)}{E_{\mathrm{d}}(\mathrm{PAR}, 0)}=\frac{2 \ln 10}{K_{\mathrm{d}}(\mathrm{PAR})}=\frac{4.605}{K_{\mathrm{d}}(\mathrm{PAR})}
$$

张运林等 ${ }^{[20]}$ 通过对 2004年10月20-29日的67个采样点的实测数据进行分析, 认为非色素颗粒物和 浮游植物色素能解释 $97.9 \%$ 的漫射衰减系数变化, 而真光层深度与漫射衰减系数存在着如公式 6 所示的 定量关系，因此真光层的计算可以通过漫射衰减系数与非色素颗粒物与叶绿素a浓度的经验关系加以 确定.

将2003-2007年对全湖共进行的14次采样的298个采样点，按非色素颗粒浓度从大到小的顺序排列， 每隔 3 个点取出 1 个点, 剩余的 199 个点用来建立模型, 在SPSS中对漫射衰减系数与非色素颗粒物、叶绿素 a浓度进行多元回归分析, 结果如下:

$$
K_{\mathrm{d}}(\mathrm{PAR})=0.062( \pm 0.001) C_{\text {Tripton }}+0.011( \pm 0.001) C_{\text {Chl.a }}+1.430( \pm 0.079)\left(n=199, r^{2}=0.954, P<0.0001\right)
$$

将取出的 99 个点的非色素颗粒物、叶绿素a浓度代人式(7), 计算得到漫射衰减系数, 与实测值的对比 得到平均相对误差为 $11.7 \%$. 由此可见, 由非色素颗粒物和叶绿素a浓度能非常准确的估算得到PAR漫射 衰减系数, 其计算式如下: 


\section{2 非色素颗粒物遥感反演}

$$
Z_{\text {eu }}(\mathrm{PAR})=4.605 /\left(0.062 \mathrm{C}_{\text {Tripton }}+0.011 C_{\text {Chl.a }}+1.430\right)
$$

太湖冬、夏两季各类水质参数浓度如下: 冬季非色素颗粒物的变化范围为 $18.7-281.7 \mathrm{mg} / \mathrm{L}$, 均值为 $127.9 \mathrm{mg} / \mathrm{L}$, 叶绿素 $\mathrm{a}$ 的变化范围为 $5.3-34.0 \mu \mathrm{g} / \mathrm{L}$, 均值为 $13.0 \mu \mathrm{g} / \mathrm{L}$; 夏季非色素颗粒物的变化范围为 $11.8-94.1 \mathrm{mg} / \mathrm{L}$, 均值为 $43.2 \mathrm{mg} / \mathrm{L}$, 叶绿素 $\mathrm{a}$ 的变化范围为 $4.8-360.7 \mu \mathrm{g} / \mathrm{L}$, 均值为 $50.6 \mu \mathrm{g} / \mathrm{L}$. 冬夏两季水质 参数浓度存在着较大的差异, 为了获得良好的反演精度, 采取分季节分别建立两项参数的反演模型.

为寻找反演太湖非色素颗粒物最合适的波段组合, 在SPSS支持下, 计算TM各个波段、波段组合与非 色素颗粒物浓度之间的PEARSON相关关系. 结果表明冬季非色素颗粒浓度与(b3+b4)/b5相关系数最高, 夏季非色素颗粒浓度与 $(\mathrm{b} 3+\mathrm{b} 1) / 2$ 相关系数最高, 故分别选择(b3+b4)/b5、(b3+b1)/2来反演冬、夏两季非色 素颗粒浓度. 剔除受天空状况和水面藻华影响严重的站点, 有效站点个数冬季为 44 , 夏季为 42 , 将其按 从小到大的顺序排列，每隔 3 个点取出 1 个点，剩余的点用来建立模型，取出的点用来检验模型，最后得 到冬夏两季非色素颗粒物反演模型(表1).

表 1 基于 $\mathrm{TM}$ 影像的非色素颗粒物和叶绿素 $\mathrm{a}$ 遥感估测模型与误差描述 Tab.1 Models and relative errors of estimation of tripton and chlorophyll-a (Chl.a) concentrations based on TM images

\begin{tabular}{ccccccc}
\hline 序号 & 反演参数 & 季节 & 模型 & $r$ & $P$ & $\begin{array}{c}\text { 平均相对 } \\
\text { 误差(\%) }\end{array}$ \\
\hline 1 & 非色素颗粒物 & 冬季 & $C_{\text {Tripton }}=-36.302+44.089((\mathrm{~b} 3+\mathrm{b} 4) / \mathrm{b} 5)$ & 0.753 & $<0.001$ & 27.1 \\
2 & 非色素颗粒物 & 夏季 & $C_{\text {Tripton }}=-102.363+1021.471((\mathrm{~b} 3+\mathrm{b} 1) / 2)$ & 0.713 & $<0.001$ & 30.8 \\
3 & 叶绿素 a & 冬季 & $C_{\text {Chl.a }}=-12.326+3.79 b 3$ & 0.722 & $<0.001$ & 23.0 \\
4 & 叶绿素 a & 夏季 & $\ln C_{\text {Chl.a }}=5.325+6.429 N D V I$ & 0.694 & $<0.001$ & 42.5 \\
\hline
\end{tabular}

对两期TM影像分别应用表1中的模型1、2逐像元估测太湖的冬夏两季非色素颗粒物浓度(图2). 太湖 非色素颗粒物的区域分布为湖心区最高, 其次是梅梁湾、竺山湾和胥口湾, 东太湖的浓度最低. 非色素颗 粒物浓度的空间分布究其本质, 主要是由于风浪、湖区位置、浮游藻类及水中高等植物生长分布共同作 用的结果(图2). 湖心区非色素颗粒物浓度最高, 这是由于湖心区开阔, 风速较大, 年月平均风速要比湖 岸大 $0.5-1 \mathrm{~m} / \mathrm{s}^{[22]}$, 在风浪作用下底泥发生再悬浮. 非色素颗粒物最低值发生在东太湖是由于东太湖位于 太湖东南部的一个狭长湖湾, 受风浪的作用小, 再加上东太湖的沉水植物和挺水植物对水体起着过滤、 净化、消浪和抑制底泥上浮的作用 ${ }^{[23]}$. 从不同的季节来看, 对反演出的非色素颗粒物浓度进行统计, 冬季 浓度为 $0.0-255.8 \mathrm{mg} / \mathrm{L}$, 平均值为 $119.4 \mathrm{mg} / \mathrm{L}$; 夏季浓度为 $0.0-206.8 \mathrm{mg} / \mathrm{L}$, 平均值为 $44.3 \mathrm{mg} / \mathrm{L}$. 遥感反演得 到冬、夏两季非色素颗粒物浓度均出现了 0 值, 对所有的 0 值点进行统计, 冬夏两季分别仅占全湖的 $0.07 \%$ 和 $0.65 \%$, 可以认为是影像噪声引起的, 因此并不影响反演结果. 冬季的变化范围、平均值均明显高于夏 季, 主要是由于不同季节风速、风向不一样, 加之动植物季节生长差异所致. 2007年冬季采样前经历了一 次大风浪过程，据太湖湖泊生态系统研究站自动气象观测记录采样前 $1 \mathrm{~d}$ 每 $10 \mathrm{~min}$ 平均风速达 $6.1 \mathrm{~m} / \mathrm{s}$. 风浪 引起的沉积物再悬浮明显增加水体中非色素颗粒物浓度. 而夏季风速小, 持续时间短, 采样前一天平均 风速仅 $2.4 \mathrm{~m} / \mathrm{s}$, 风浪引起的沉积物再悬浮不如冬季明显, 并且冬季水生植物处于越冬期, 对悬浮物过滤、 抑制底泥上浮的作用明显减弱.

\section{3 叶绿素a浓度遥感反演}

马荣华等认为 $\mathrm{TM}$ 第 2 、第 3 和第 4 波段是太湖夏季叶绿素的敏感波段, 并基于 $\mathrm{TM}$ 第 3 波段建立了 $r^{2}$ 分别为 0.551 和 0.651 的两个叶绿素反演模型, 反演误差在 6.96\%-174.3\%之间 ${ }^{[24]}$. 本研究为寻找反演太 湖叶绿素 a 最合适的波段组合, 在 SPSS 支持下, 计算 TM 各个波段、波段组合与叶绿素浓度之间的 PEARSON 相关关系, 结果表明冬季叶绿素 a 浓度与 b3 相关系数最高, 夏季叶绿素 a 浓度与植被指数 $\operatorname{NDVI}((\mathrm{b} 4-\mathrm{b} 3) /(\mathrm{b} 4+\mathrm{b} 3))$ 相关系数最高. 因此分别选择 b3 和(b4-b3)/(b4+b3)的值来反演太湖冬、夏季叶绿 
素 a 浓度. 模型的建立方法同悬浮物, 反演模型如表 1 . 对两期 TM 影像分别应用表 1 中的模型 $3 、 4$ 逐像 元估测太湖的冬夏两季叶绿素 a 浓度, 结果如图 3 所示.

太湖水体冬、夏两季叶绿素 $\mathrm{a}$ 浓度差别非常大, 冬季浓度为 $2.1-28.4 \mu \mathrm{g} / \mathrm{L}$, 平均值为 $10.9 \mu \mathrm{g} / \mathrm{L}$, 夏季浓 度为 $0.0-3004.0 \mu \mathrm{g} / \mathrm{L}$, 平均值为 $115.1 \mu \mathrm{g} / \mathrm{L}$, 虽然浓度差别很大, 但总体趋势是南太湖<湖心区、胥口湾 $<$ 梅 梁湾、笈山湾. 图3可看出, 2006年8月 1 号, 全湖的叶绿素a浓度偏高, 叶绿素a浓度最高的点出现在梅梁湾 口、竺山湾西北部沿岸区以及太湖西部近岸区, 三区的叶绿素浓度都大于 $100 \mu \mathrm{g} / \mathrm{L}$, 是水华最严重的区域, 这与采样期间现场记录相符. 太湖水华一般从 4-5月份开始暴发, 水华覆盖面积一直比较大, 采样的7-8 月份期间是水华暴发最严重的季节，以上三区湖面漂浮着大量的蓝藻. 此外在湖的大部分边缘区即水陆 交接处, 叶绿素的浓度也偏高, 这一方面是由于水华易在岸边带堆积, 另一方面与岸边带芦苇分布以及 湖边陆地植被干扰有关. 南面的湖州附近以及西山岛北面部分湖区叶绿素浓度最低.

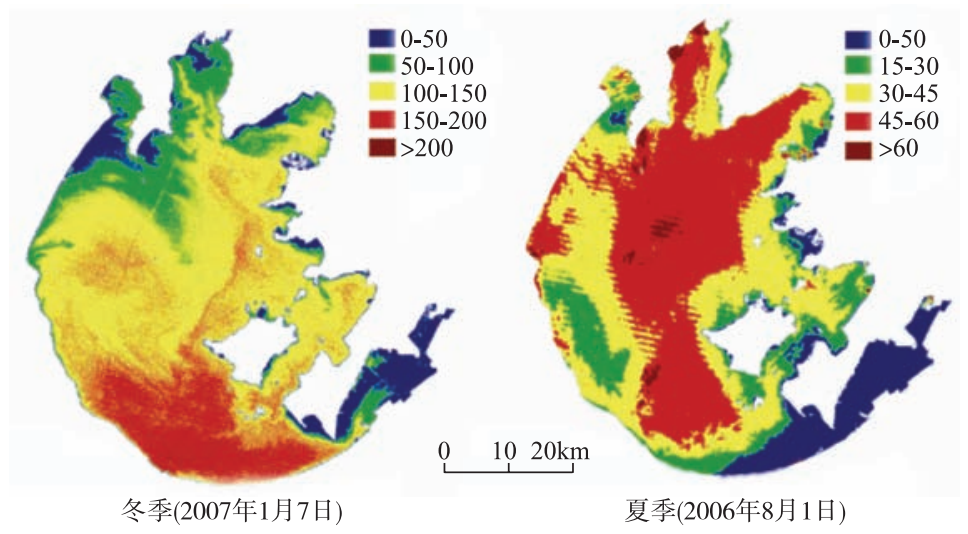

图2 太湖冬、夏两季非色素颗粒物浓度 $(\mathrm{mg} / \mathrm{L})$ 分布

Fig.2 Spatial distribution of Tripton concentration(mg/L) of Lake Taihu in winter and summer

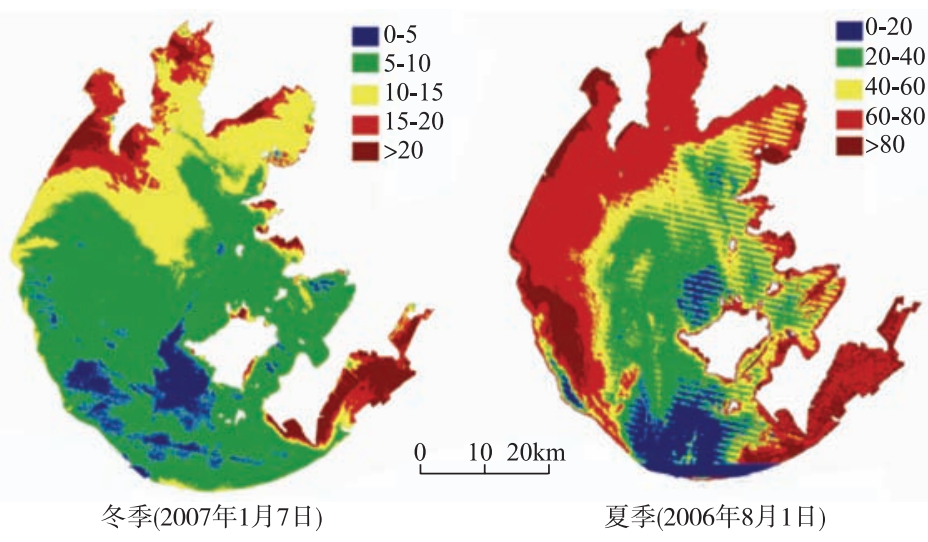

图3 太湖冬、夏两季叶绿素a浓度 $(\mu \mathrm{g} / \mathrm{L})$ 分布

Fig.3 Spatial distribution of Chl.a concentration $(\mu \mathrm{g} / \mathrm{L})$ of Lake Taihu in winter and summer

东太湖在冬、夏两季均显示出叶绿素浓度很高，而实际东太湖大部分水体较为清澈，处于中营养水

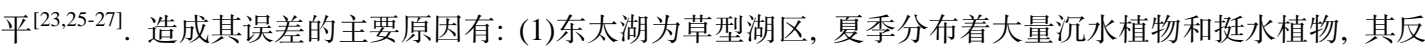
射光谱特征与蓝藻极为相似, 在 $680 \mathrm{~nm}$ 存在明显谷值, 而在 $720 \mathrm{~nm}$ 和 $810 \mathrm{~nm}$ 分别存在明显峰值, 对应着叶 绿素a反演的 $\mathrm{TM}$ 第3、4波段 ${ }^{[28]}$. 由于 TM影像波段数较少, 波段范围较宽, 因此不能很好的区分两者, 从 
而造成了估测值误差; (2)湖中过多过密的网围养殖等人工设施影响了影像的辐亮度, 在一定程度上也会 造成误差; (3)此次采样东太湖并没有相应的采样点, 也是造成误差的原因之一.

\section{4 真光层深度时空变化}

将前面反演得到的非色素颗粒物浓度和叶绿素a浓度, 代人公式(8): $Z_{\mathrm{eu}}(\mathrm{PAR})=4.605 /\left(0.062 \mathrm{C}_{\text {Tripton }}\right.$ $+0.011 C_{\text {Chl.a }}+1.430$ ), 对 TM影像逐像元估算太湖冬夏两季真光层深度, 得到真光层深度的理论分布值, 然 后与湖底地形数据进行叠加分析, 真光层深度理论值大于水深的点用水深代替, 最后结果如图 4 所示. 对 整个湖区真光层深度进行分季节统计分析, 冬季真光层深度变化范围在 $0.26-2.28 \mathrm{~m}$ 之间, 平均值为 $0.56 \mathrm{~m}$, 标准差为 $0.23 \mathrm{~m}$, 夏季真光层深度变化范围在 $0.20-2.22 \mathrm{~m}$ 之间, 平均值为 $0.98 \mathrm{~m}$, 标准差为 $0.25 \mathrm{~m}$, 夏季真 光层深度平均值明显大于冬季, 是冬季的1.75倍.

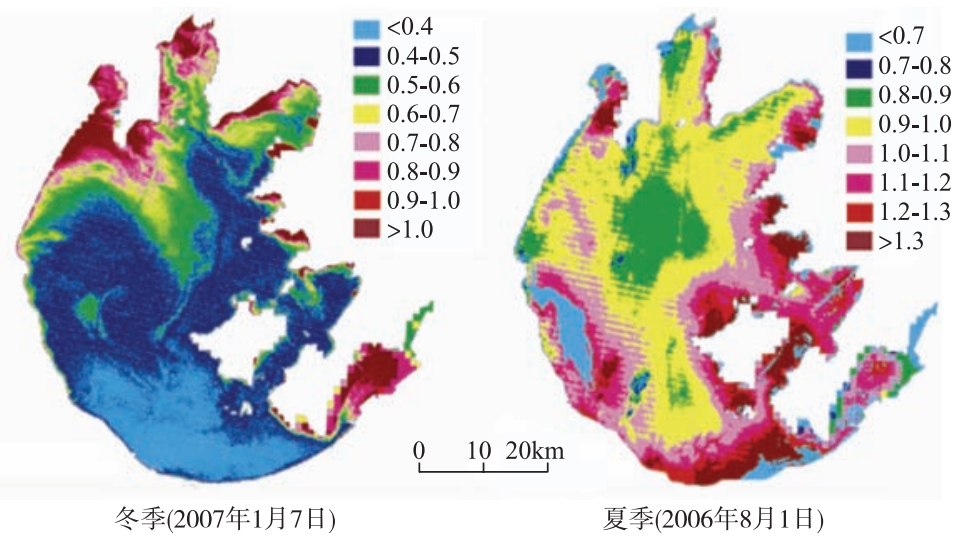

图4 太湖冬夏两季真光层深度 $(\mathrm{m})$ 分布

Fig.4 Spatial distribution of euphotic depth(m) in Lake Taihu

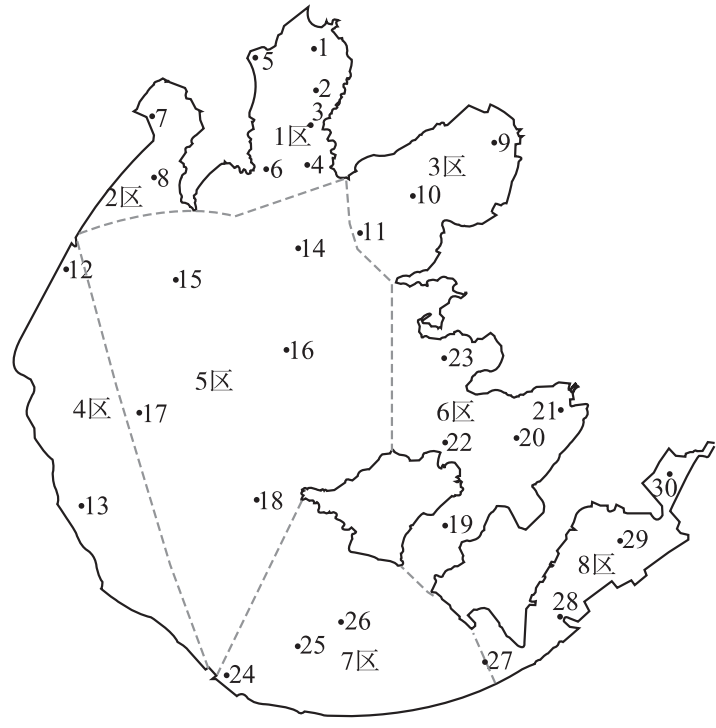

图5 真光层深度分区统计站点分布

Fig.5 Subarea and distribution of sampling stations of euphotic depth

为了更直观的了解真光层深度在时空上的分 布规律，本文将整个太湖地区分为 8 个区域，对各 个区域的真光层深度进行统计分析, 统计的结果 如表2, 同时选取 30 个散布在 8 个区的样点, 分别 提取冬、夏两季的真光层深度, 对比结果如表3. 从图4以及表2、3可以看出，(1)从空间上看，冬季 时真光层平均深度的变化规律为: 南太湖 $<$ 西部 沿岸 $<$ 湖心 区 $<$ 胥口湾 $<$ 贡湖湾 $<$ 梅梁湾 $<$ 东太湖 $<$ 竺山湾; 夏季时的变化规律为: 西部沿岸 $<$ 梅梁湾 $<$ 东太湖<湖心区 $<$ 贡湖湾 $<$ 䇥山湾 $<$ 南太湖 $<$ 胥口 湾. 与张运林等利用1993-2003年实测悬浮物浓 度计算得到的典型湖区真光层深度的空间分布总 体上较为一致, 西部沿岸开阔区和湖心区真光层 深度一般都较低 ${ }^{[18]}$. 但东太湖的结果存在较大的 出人, 这主要是由于东太湖受沉水植物和围网养 殖的影响, 叶绿素a遥感反演结果有明显误差. 从 图3可以看出不论冬夏季东太湖的叶绿素a浓度遥 感反演结果都非常高, 甚至高出北部藻型湖区很 多, 从而造成基于非色素颗粒物和叶绿素a浓度计

算得到的真光层深度明显下降. 因而研究如何消除沉水植物对叶绿素a浓度反演的影响对于真光层深度 
的遥感反演同样显得非常重要. (2)从季节上看, 全湖夏季真光层平均深度大于冬季, 对表 4 中 30 个站点真 光层深度进行组间方差分析, 发现存在显著性季节差异(ANOVA, $P<0.001$ ). 但不同的湖区真光层深度季 节变化还是存在一定差异, 其中梅梁湾、贡湖湾、西部沿岸、湖心区、胥口湾、南太湖夏季真光层深度 明显大于冬季, 而竺山湾和东太湖夏冬变化则不是很明显. (3)同一季节, 同一湖区内部, 真光层的变化也 显示出一定的规律性: 冬季时, 梅梁湾、竺山湾、东太湖内部真光层变化比较明显, 梅梁湾的真光层深度 呈现从湾内向湾口逐渐降低的趋势, 竺山湾的真光层深度与前者呈相反的趋势, 从湾内向湾口逐渐增加, 东太湖中心区域的真光层深度要明显大于其他区域, 而胥口湾、贡湖湾、湖心区以及南太湖湖区内的变 化不是很明显; 夏季时, 同一湖区内真光层的变化规律与冬季基本一致, 只有梅梁湾的真光层深度变化 趋势与冬季相反, 从湾内向湾口逐渐递增.

表 2 太湖冬夏两季真光层深度的分区统计值(单位: $\mathrm{m}$ )

Tab.2 The statistics of euphotic depth in different regions of Lake Taihu in winter and summer

\begin{tabular}{|c|c|c|c|c|c|c|c|c|c|c|c|c|c|c|c|c|}
\hline \multirow{2}{*}{$\begin{array}{l}\text { 分区 } \\
\text { 季节 }\end{array}$} & \multicolumn{2}{|c|}{$\begin{array}{c}1 \text { 区 } \\
\text { (梅梁湾) }\end{array}$} & \multicolumn{2}{|c|}{$\begin{array}{c}2 \text { 区 } \\
\text { (竺山湾) }\end{array}$} & \multicolumn{2}{|c|}{$\begin{array}{c}3 \text { 区 } \\
\text { (贡湖湾) }\end{array}$} & \multicolumn{2}{|c|}{$\begin{array}{c}4 \text { 区 } \\
\text { (西岸区) }\end{array}$} & \multicolumn{2}{|c|}{$\begin{array}{c}5 \text { 区 } \\
\text { (湖心区) }\end{array}$} & \multicolumn{2}{|c|}{$\begin{array}{c}6 \text { 区 } \\
\text { (胥口湾) }\end{array}$} & \multicolumn{2}{|c|}{$\begin{array}{c}7 区 \\
\text { (南太湖) }\end{array}$} & \multicolumn{2}{|c|}{$\begin{array}{c}8 \text { 区 } \\
\text { (东太湖) }\end{array}$} \\
\hline & 冬 & & 冬 & & 冬 & & 冬 & & 冬 & 夏 & 冬 & 百 & 冬 & 夏 & 冬 & 夏 \\
\hline 小保 & & & & & & & & & & & & & & & & \\
\hline & & & & & 21 & & ס & & & & 27 & & & & & \\
\hline & .77 & & & & .01 & & & & & & 0.02 & & & & 0.82 & \\
\hline 准差 & 0.26 & .13 & .20 & .27 & .24 & .13 & 0.11 & 0.26 & 0.11 & 0.14 & 0.18 & 0.20 & 0.08 & 0.13 & 0.23 & 0.30 \\
\hline
\end{tabular}

表 3 太湖冬夏两季 30 个样点的真光层深度值(单位: $m$ )

Tab.3 Comparison of euphotic depth of 30 sampling stations in Lake Taihu in winter and summer

\begin{tabular}{cccccccccccccccc}
\hline 站点 & 1 & 2 & 3 & 4 & 5 & 6 & 7 & 8 & 9 & 10 & 11 & 12 & 13 & 14 & 15 \\
\hline 冬季 & 0.88 & 0.76 & 0.66 & 0.53 & 0.68 & 0.64 & 0.78 & 1.12 & 0.68 & 0.67 & 0.51 & 0.70 & 0.47 & 0.47 & 0.47 \\
夏季 & 0.95 & 0.96 & 0.94 & 0.98 & 0.66 & 0.90 & 0.32 & 1.33 & 1.01 & 0.90 & 1.00 & 0.89 & 1.06 & 0.90 & 0.88 \\
\hline 站点 & 16 & 17 & 18 & 19 & 20 & 21 & 22 & 23 & 24 & 25 & 26 & 27 & 28 & 29 & 30 \\
\hline 冬季 & 0.57 & 0.44 & 0.50 & 0.47 & 0.58 & 0.43 & 0.47 & 0.53 & 0.38 & 0.40 & 0.40 & 0.43 & 0.52 & 1.20 & 0.50 \\
夏季 & 0.88 & 1.01 & 0.94 & 1.55 & 1.13 & 1.15 & 1.08 & 1.27 & 1.16 & 1.00 & 0.96 & 0.87 & 0.96 & 1.20 & 0.50 \\
\hline
\end{tabular}

\section{3 结论}

(1)非色素颗粒物空间分布的总体趋势为湖心区最高, 其次是梅梁湾、竺山湾和胥口湾, 东太湖的浓 度最低; 冬夏两季浓度差别比较大, 冬季的变化范围、平均值均明显高于夏季.

(2)冬夏两季叶绿素 a 浓度空间分布的总体趋势是南太湖-湖心区、胥口湾-梅梁湾、竺山湾浓度逐渐 增加; 夏季水华的全面暴发, 引起叶绿素 a 浓度普遍偏高.

(3)太湖真光层深度分布存在显著的时空差异. 从空间上看, 冬季真光层深度的变化规律为: 南太湖 $<$ 西部沿岸<湖心区 $<$ 胥口湾 <贡湖湾 <梅梁湾 $<$ 东太湖 $<$ 竺山湾; 夏季时的变化规律为: 西部沿岸 <梅梁湾 $<$ 东太湖 $<$ 湖心区 $<$ 贡湖湾 $<$ 笔山湾 $<$ 南太湖 $<$ 胥口湾. 从季节上看, 夏季真光层平均深度显著大于冬季, 但 不同湖区其季节变化存在一定差异. 对于同一季节同一湖区内部, 真光层深度的变化也不尽一致, 如冬 季时梅梁湾的真光层深度呈现从湾内向湾口逐渐降低的趋势, 而管山湾则恰好相反.

(4)受沉水植物影响东太湖冬、夏季遥感反演的叶绿素均明显偏高, 从而造成计算得到的真光层深 度偏低. 因此如何消除沉水植物对叶绿素a浓度遥感反演的影响是未来提高真光层深度遥感反演精度 的关键.

致谢: 野外采样得到冯胜、王錂、赵巧华、李俊生、张浩等同志的鼎力帮助, 在此一并表示谢意. 


\section{4 参考文献}

[1] Reinart A, Arst H, Erm A et al. Optical and biological properties of Lake Ülemiste, water reservoir of the city of Tallinn II: Light climate in Lake Ülemiste. Lakes \& Reservoirs: Research and Management, 2001, 6: 75-84.

[2] Kirk JTO. Light and photosynthesis in aquatic ecosystem. Cambridge, Britain: Cambridge University Press, 1994, 47-144.

[3] Hinojosa FD, Castro GG, Zavala JAS et al. The effect of vertical mixing on primary production in a bay of the Gulf of California. Estuar Coast Shelf S, 1997, 45: 135-148.

[4] Oliver RL, Whittington J, Lorenz Z et al. The influence of vertical mixing on the photoinhibition of variable chlorophyll $a$ fluorescence and its inclusion in a model of phytoplankton photosynthesis. J Plankton Res, 2003, 25(9): 1107-1129.

[5] Holmes RW. The secchi disk in turbid coastal waters. Limnol Oceanogr, 1970, 15: 688-694.

[6] Kratzer S, Häkansson B, Sahlin C. Assessing secchi and photic zone depth in the Baltic Sea from satellite data. Ambio, 2003, 32(8): 577-585.

[7] 费尊乐. 近海水域漫射衰减系数的估算. 黄渤海海洋, 1984, 2(1): 26-29.

[8] 曹文熙, 黄良民. 海洋生物-光学研究进展与展望. 自然科学进展, 2004, 14(1): 20-27.

[9] 曹文熙, 杨跃忠. 海洋光合有效辐射分布的计算模式. 热带海洋学报, 2002, 21(3): 47-54.

[10] Austin RW, Petzold TJ. The determination of the diffuse attenuation coefficient of sea water using the Coastal Zone Color Scanner. In: Gower JFR ed. Oceanography from Space. New York: Plenum Press, 1981: 239-256.

[11] Austin RW, Petzold TJ. Spectral dependence of the diffuse attenuation coefficient of light in ocean waters a reexamination using new data. SPIE: Ocean Optics, 1990: 1302.

[12] Cervantes-Duarte R, Mueller JL, Trees CC et al. Euphotic depth, irradiance attenuation and remote sensing K490 in bi0-optical provinces of the Gulf of California. Ciencias Marina, 2000, 26(4): 533-560.

[13] Morel A, Berthon JF. Surface pigments, algal biomass profiles and potential production of the euphotic layer: Relationships reinvestigated in view of remote-sensing applications. Limnol Oceanogr, 1989, 34: 1545-1562.

[14] Woźniak B, Dera J, Ficek D et al. Modeling light and photosynthesis in the marine environment. Oceanologia, 2003, 45(1): $171-245$.

[15] Irigoien X, Castel J. Light limitation and distribution of chlorophyll pigments in a highly turbid estuary: the Gironde (SW France). Estuar Coast Shelf S, 1997, 44: 507-517.

[16] 李国胜, 梁 强, 李柏良. 东海真光层深度的遥感反演与影响机制研究. 自然科学进展, 2003, 13(1): 90-94.

[17] Garibaldi L, Anzani A, Marieni A et al. Studies on the phytoplankton of the deep subalpine Lake Iseo. J Limnol, 2003, 62(2): 177-189.

[18] 张运林, 秦伯强, 胡维平等. 太湖典型湖区真光层深度的时空变化及其生态意义. 中国科学(D 辑), 地球科学, 2006, 36(3): 287-296

[19] Zhang YL, Qin BQ, Liu ML. Temporal-spatial variations of chlorophyll a and primary production in Meiliang Bay, Lake Taihu, China from 1995 to 2003. J Plankton Res, 2007, 29(8): 707-719.

[20] 张运林, 冯 胜, 马荣华等.太湖秋季真光层深度空间分布及浮游植物初级生产力的估算. 湖泊科学, 2008, 20(3): 380-388.

[21] 陈宇炜, 高锡云. 浮游植物叶绿素 a 含量测定方法的比较测定. 湖泊科学, 2000, 12(2): 185-188.

[22] 孙顺才, 黄渏平. 太湖. 北京: 海洋出版社, 1993: 10-11.

[23] 张运林, 秦伯强, 陈伟民等. 太湖水体中悬浮物研究. 长江流域资源与环境, 2004, 13(3): 266-271.

[24] 马荣华, 戴锦芳. 结合 Landsat ETM 与实测光谱估测太湖叶绿素及悬浮物. 湖泊科学, 2005, 17(2): 97-103.

[25] 张运林, 秦伯强, 陈伟民等. 太湖水体透明度的分析、变化及相关分析. 海洋湖沼通报, 2003, (2): 30-36.

[26] 张运林, 秦伯强. 基于水体固有光学特性的太湖浮游植物色素的定量反演. 环境科学, 2006, 27(12): 2439-2444.

[27] 白秀玲, 谷孝鸿, 杨龙元. 东太湖水环境现状及保护对策. 湖泊科学, 2006, 18(1): 91-96.

[28] 袁 琳, 张利权. 大型沉水植物狐尾藻不同盖度的光谱特征. 遥感学报, 2007, 11(4): 609-616. 